\title{
MAN=LIFTING and other
}

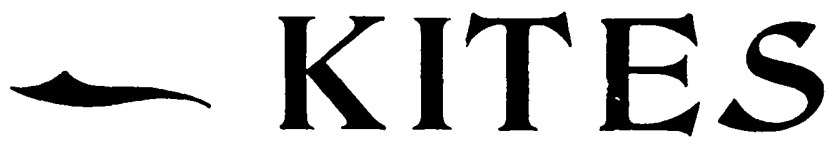

(Baden-Powell Patent)

In various sizes. Usual size $\mathrm{I} 2 \mathrm{ft}$. $X \mathrm{I} 2 \mathrm{ft}$. (of which 4 to 6 will lift a ma1 price $f_{2} 27$ s. each; $6 \mathrm{ft} . \times 6 \mathrm{ft}$. (for registering instruments, \&c.), $£ \mathrm{I}$ 5s. each.

\section{J O H N J. JACKSON, \\ YACHT AND CANOE SAIL MAKER, NORTHWICH, CHESHIRE.}

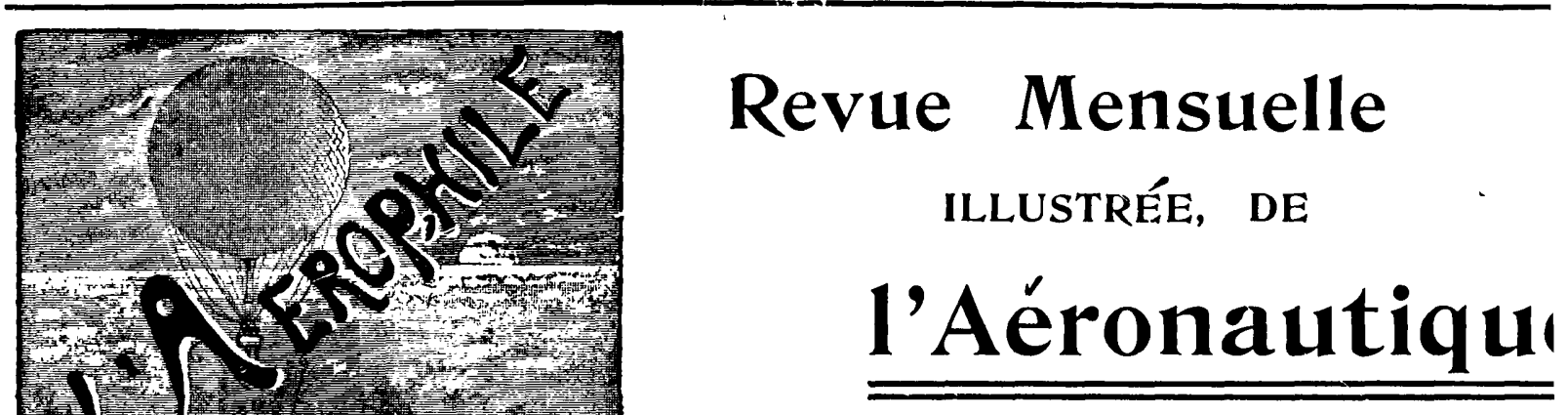

Et des Sciences qui s'y rattachent.

Publiee avec la collaboration des principaux $==$ savants francais et etranger.

Rédaction et Administration:- $\mathrm{I} 4$, Rue des Grandes-Carrières, PARIS Téléphone 503-24.

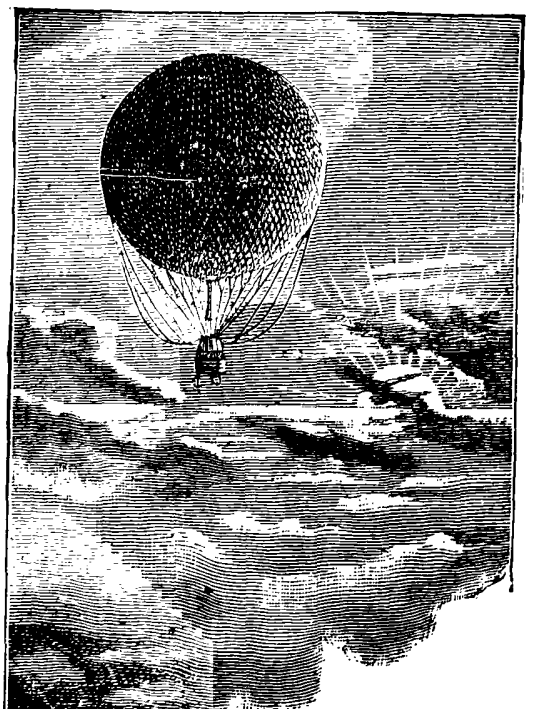

\section{GEORGES BESANCON}

OFFICIER d'ACADEMIE,

INGENIEUR AERONAUTE.

Expériences et ascensions scientifiques.

Voyages aériéns d'amateurs.

Exploration des hautes régions de l'atmosphère pa ballons sondes et Cerfs-Volants.

14 Construction de tous les appareils concernant la locomotion aeriénnt

\section{Rue des Grandes-Carrieres 14, PHRIS, MONTMARTRE.}




\section{G. SPENCER \& SONS, Salloon Manufacturers,}

GAS BALLOONS. * HOT AIR BALLOONS. .* PARACHUTES * CAPTIVE ADVERTISING BALLOONS *

\section{BALLOONS OF EVERY DESCRIPTION AND SIZE}

Of Silk, Balloon Fabric, India=Rubber, Goldbeaters' Skin, Paper, \&c.

PRICE LIST UPON APPLICATION.

BALLOON ASCENTS, PARACHUTE DESCENTS, CAPTIVE BALLOONS And other Aeronautical Attractions,

For FETES, GALAS, CARNIVALS, FlOWER SHOWS, \&c.

Undertaken by Messrs. SPENCER BROTHERS, Aeronauts.

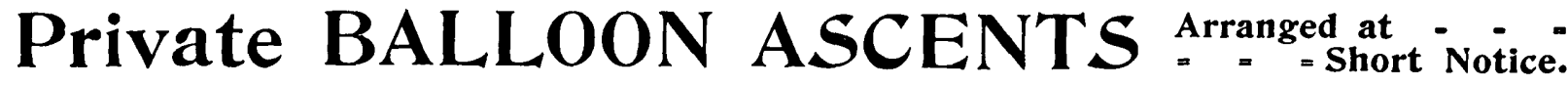
56a, HIGHBURY GROVE, ISLINGTON, LONDON, N.

๔ ILLUSTRIRTE 2 ?

\section{AERONAUTISCHE MITTHEILUNGEN}

Fachzeitschrift für alle Interessen der Flugtechnik mit ihren Hülfswissen - schaften, für aëronautische Industrie und Unternehmungen.

$==($ Illustrated Aeronautical Record $)==$

Quarterly Journal of Aeronautics.

With the collaboration of the Aeronautical Societies of Munich and of the Upper Rhine (Germany).

Edited by Dr. R. EMDEN.

Price per Annum (4 Nos.) - - - - - 6s, 10d. post free. 